\title{
How Consumers Are Affected by the Framing of Attribute Information Before and After Consuming the Product
}

\author{
IRWIN P. LEVIN \\ GARY J. GAETH*
}

\begin{abstract}
Consumers rated several qualitative attributes of ground beef that framed the beef as either " $75 \%$ lean " or " $25 \%$ fat." The consumers' evaluations were more favorable toward the beef labeled " $75 \%$ lean" than that labeled " $25 \%$ fat." More importantly, the magnitude of this information framing effect lessened when consumers actually tasted the meat. We discuss these results in terms of an averaging model, which suggests that a diagnostic product experience dilutes the impact of information traming.
\end{abstract}

$\mathrm{J}$ udgment and decision making research identifies various contexts or "framing" effects that have important implications for consumer behavior theory development and application. Our present research explores an information framing effect by which consumers' product judgments vary as a function of the verbal labels used to define specific product attributes (Johnson and Levin 1985; Levin et al. 1985). For example, the judged likelihood of purchasing ground beef was found to be higher when the ground beef was described (framed) in terms of its percent-lean rather than its percent-fat (Levin et al. 1985).

We used a more general operational definition of framing than used in earlier works based on Kahneman and Tversky's Prospect Theory (Kahneman and Tversky 1979; see also Puto 1987; Thaler 1985; Tversky and Kahneman 1981). These researchers defined framing effect in the context of choice under uncertainty, where the choice between two alternative actions was shown to reverse, depending on whether attention was focused on the potential gain or the potential loss associated with each alternative. This definition applies to areas that require discrete choices between opposing courses of action that are typically assessed by probabilities of gains and losses (e.g. Neale and Bazerman 1985). In contrast, the present study examines the effect of deterministic product

-Irwin P. Levin is Professor of Psychology, College of Liberal Arts, and Gary J. Gaeth is Assistant Professor of Marketing. College of Business, both at the University of lowa, lowa City, IA 52242. The authors wish to thank three anonymous reviewers for their useful suggestions, Ross Dickerson and Elizabeth Vera for their help in conducting the research, and Ginny Parrish for her editorial assistance. attribute framing on consumers' overall product judgments.

To better understand this effect, Levin (1987) showed that favorable or unfavorable associations with positively or negatively phrased attribute labels mediate the evaluation of consumer goods. Different groups of subjects in that study were asked to evaluate a hypothetical purchase of ground beef that was alternatively described as " $75 \%$ lean" or " $25 \%$ fat." Subjects' evaluations were made on several scales, such as greasy/greaseless, good tasting/bad tasting, and high quality/low quality. More favorable associations were produced on each scale when the beef was described in terms of percent-lean rather than percent-fat.

Exposure to externally generated product frames is but one part of the consumer information process. Another critical part of the process that has been included in many of the recent descriptions of consumer behavior is personal product experience (see Assael 1987; Bettman 1979; Bettman and Park 1980). Our present study examines the joint effects that framed product attribute information and personal product experience have on consumer judgments. (See Deighton and Schindler 1988 for an assessment of the interaction of advertising and experience with a service.) To manipulate experience with the product, we gave subjects a taste of ground beef that was also described verbally to them as either percent-lean or percent-fat. This procedure allowed us to assess whether the information frame affects consumer judgments in addition to the effects of personal product experience.

We varied the order of the framing and sampling stages; some subjects tasted the meat before it was la- 
beled, whereas other subjects tasted the meat after the verbal label. We manipulated the order to reveal how the framing of attribute information would affect consumers' decisions in two typical sequences of events (i.e., when consumers are exposed to product information before they have any personal experience with the product and when personal experience with the product precedes consumers' exposure to product information.) Considerable evidence in the marketing literature suggests that product labeling can have an impact on consumers' decisions prior to firsthand product experience. For example, in their classic study, Allison and Uhl (1964) show that consumers perceive beers differently depending on whether the consumers are aware or unaware of the brand of the beer. Similarly, Bettman and Sujan (1987) show that "priming" customers to use different decision criteria affected the consumers' differential use of decision attributes.

Indeed, an argument can be made that a major role of advertising is to frame the subsequent product experience. Deighton suggests that "advertising arouses an expectation" and "the subject tends to confirm the expectation upon exposure to more objective information (such as evidence or product experience)" (1984, p. 765). Deighton (1984; see also Darley and Gross 1983) also shows that exposure to advertising influenced consumer inferences drawn from objective information provided later by an "unbiased" source (e.g., Consumer Reports). Hoch and $\mathrm{Ha}$ (1986, Experiment 1) extend Deighton's work by demonstrating that advertising has its greatest influence when it precedes an ambiguous product experience yet has very little impact when it succeeds an unam: biguous product experience. They also showed that an ad that precedes product experience has a significant influence on product evaluation when compared to a no ad control condition, whereas an ad that followed product experience was not significantly different from the no ad control condition. In our context, it seems reasonable to treat an advertisement as a frame. Hoch and Ha's (1986) research suggests that the framing effect will be strongest when the product experience is nondiagnostic (ambiguous) and it will be weakest (or overwhelmed) when the product experience is diagnostic (unambiguous).

To model the joint effects of frame and experience, we view the judgment process as a classic example of integrating information from different sources. Information Integration Theory (Anderson 1981, 1986) provides methods for testing alternative algebraic models that describe the information integration process. Tests of adding versus averaging models have proved particularly useful in understanding consumer behavior (Shanteau 1988; Troutman and Shanteau 1976) and are especially relevant to the present study. An adding model predicts that the effect of a given source of information will be independent of the number and nature of the other sources with which it is combined. An averaging model, in contrast, predicts that the effect of any given source will be reduced with each piece of added information. Thus, an averaging model, rather than an adding model, predicts that the effect of an information frame will be reduced when the consumer has firsthand experience with the product.

\section{METHOD}

\section{Design and Procedure}

We asked subjects to rate ground beef on several qualitative dimensions based on a sample taste of the meat and on a verbal description of a key attribute. The basic design consisted of the between-subjects factorial manipulation of two levels of label (positive and negative) and two temporal orders (taste the beef after receiving the label and taste the beef before receiving the label).

Half of the subjects in the "taste after labeling" condition were told that they would be given a taste of "75\% lean ground beef" while the other half were told that they would be given a taste of " $25 \%$ fat ground beef." After tasting the meat, they were given a response sheet for expressing their reactions. Subjects in the "taste before labeling" condition were not told the "\%-lean/\%-fat" information until after they tasted the ground beef. Half of these subjects were then told that the meat they had just sampled was "75\% lean" whereas the others were told that it was " $25 \%$ fat." They then were given a response sheet.

We took several precautions during the tasting stage to minimize confounding effects. The study was conducted on two separate evenings using the same four consecutive half-hour periods per evening-one for each cell of the experimental design. One random order of conditions was employed the first evening and the reverse order was employed the second evening. On each evening, all subjects received a $1 \frac{1}{2}$ ounce sample from the same skillet of freshly cooked ground beef. (Actually, the meat was slightly more lean than the reported " $75 \%$ lean $/ 25 \%$ fat.")

The four rating scales that were on the response sheets follow. Subjects were instructed to place an $X$ in one of the seven boxes on each scale. Note that the left-right positions of the positive and negative poles vary across scales. These are the same scales used in the Levin (1987) study.

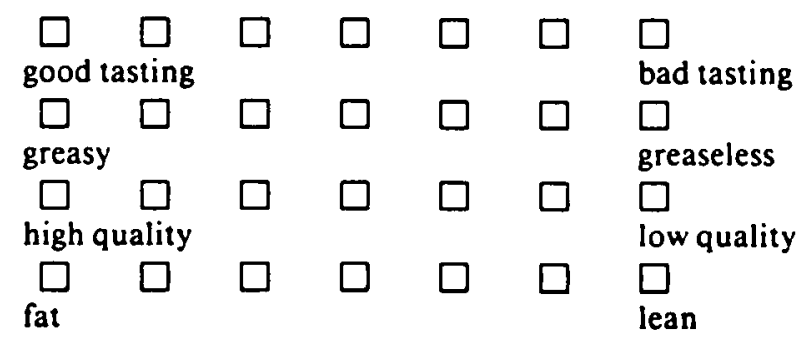


TABLE 1

MEAN RATING SCORES ACROSS TASTE AND FRAMING CONDITIONS

\begin{tabular}{|c|c|c|c|c|c|c|c|c|c|}
\hline \multirow[b]{2}{*}{ Rating scale } & \multicolumn{3}{|c|}{ Label-only condition" } & \multicolumn{3}{|c|}{ Taste after labeling } & \multicolumn{3}{|c|}{ Taste before labeling } \\
\hline & Positive & Negative & Difference $^{\circ}$ & Positive & Negative & Difference & Positive & Negative & Difference \\
\hline $\begin{array}{l}\text { Fat/lean } \\
\text { Low quality/high quality } \\
\text { Greasy/greaseless } \\
\text { Bad taste/good taste }\end{array}$ & $\begin{array}{l}5.15 \\
5.33 \\
4.49 \\
5.69\end{array}$ & $\begin{array}{l}2.83 \\
3.66 \\
2.96 \\
4.43\end{array}$ & $\begin{array}{l}2.32^{\circ} \\
1.67^{\circ} \\
1.53^{\circ} \\
1.26^{\circ}\end{array}$ & $\begin{array}{l}4.67 \\
4.71 \\
4.13 \\
5.00\end{array}$ & $\begin{array}{l}3.57 \\
3.95 \\
3.43 \\
4.71\end{array}$ & $\begin{array}{l}1.10^{\circ} \\
.76^{\circ} \\
.70^{\circ} \\
.29\end{array}$ & $\begin{array}{l}4.05 \\
4.43 \\
3.67 \\
5.00\end{array}$ & $\begin{array}{l}3.45 \\
4.09 \\
3.05 \\
5.09\end{array}$ & $\begin{array}{l}.60^{\circ} \\
.34 \\
.62^{c} \\
-.09\end{array}$ \\
\hline
\end{tabular}

- Data taken from Levin (1987).

- Difference between mean rating score in positive and negative framing conditions.

$p<0.10$.

$0<0.05$

$p<0.01$.

\section{Subjects}

Ninety-six students from introductory psychology classes at the University of lowa signed up to participate in the study the day before the actual session was to be held. Twelve males and 12 females volunteered for each of the four evening sessions, though not all of those who signed up actually showed up for their designated session. The final sample size in each experimental condition was 21 in "positive frame taste before labeling," 24 in "negative frame taste before labeling," 22 in "positive frame taste after labeling," 21 in "negative frame taste after labeling."

\section{RESULTS}

Ratings on each scale ranged from one to seven, with higher numbers representing more favorable responses. Table 1 gives the mean rating score on each scale for each experimental condition of the present study and for the Levin (1987) study, which did not include a tasting phase. We found ratings to be higher in the positive framing condition than in the negative framing condition, with one minor reversal. Differences between framing conditions were tested for significance using a one-tailed $t$-test of the hypothesis that the difference is greater than zero.

Although most, but not all, individual tests of the framing effect were significant, we detected a clear pattern in the magnitude of the difference scores in Table 1. The largest framing effect was on the fat/lean scale, which is the scale most related to the framing manipulation. The smallest effect was on the bad tasting/good tasting scale, which is the scale most related to the tasting experience. More importantly, comparing the values of the difference scores across columns in Table 1 shows that the magnitude of the framing effect within each scale was related to whether subjects actually tasted the ground beef and, to some extent, when they tasted it. For each scale, the framing effect tended to be largest when subjects did not actually taste the meat, less large when subjects tasted the meat after being given the label, and smallest when subjects tasted the meat before being given the label.

To test the significance of these observed trends, ANOVA tests were performed on the data from the four rating scales.' These results are summarized in Table 2. Framing condition accounted for the largest percentage of the variance on each scale. Tasting condition-whether the subjects tasted the meat before receiving the label, after receiving the label, or did not taste the meat at all (from Levin 1987)-was not a significant source of variance. That is, whether and when subjects tasted the meat did not affect the overall favorableness of their rating responses. However, the framing condition by tasting condition interaction was significant for three of the four scales, affirming that the magnitude of the framing effect varied across tasting conditions.

The two components of this interaction can be described as (1) the extent to which the framing effect differed between the "label-only" condition of the Levin (1987) study and the "taste plus labeling" conditions of the present study, and (2) the extent to which the framing effect differed between the "taste after labeling" and "taste before labeling" conditions of the present study. Appearing at the bottom of Table 2 as subcomponents of the framing by taste interaction, these two tests ( $1 d f$ each) show that the first component was significant for all scales. This significance confirms that the framing effect, as predicted by the averaging model, was reliably reduced when subjects tasted the meat as compared to when they did not taste the meat. The second component, however, was not significant for any scale. Thus, the order of the tasting and labeling phases did not significantly affect the magnitude of the framing effect.

\footnotetext{
'Note that the assumption of random assignment of subjects to conditions clearly has been violated in this between-experiment test. However, the subjects who participated in both experiments did come from the same population.
} 
TABLE 2

ANOVA RESULTS FOR EACH RATING SCALE

\begin{tabular}{|c|c|c|c|c|c|c|c|c|c|}
\hline Source & df & MS & $\mathbf{F}$ & MS & $\mathbf{F}$ & MS & $\mathbf{F}$ & MS & $\mathbf{F}$ \\
\hline Framing condition (positive, negative) & 1,184 & 128.10 & $54.51^{\circ}$ & 63.37 & $30.25^{\circ}$ & 61.68 & $27.28^{\circ}$ & 24.86 & $13.48^{\circ}$ \\
\hline $\begin{array}{l}\text { Taste condition (label-only." taste after labeling, taste } \\
\text { before labeling) }\end{array}$ & 2,184 & 2.23 & .95 & 1.61 & .77 & 3.23 & 1.43 & .91 & .49 \\
\hline Taste condition compared to no taste condition & 1.184 & 24.30 & $10.34^{\bullet}$ & 13.87 & $6.62^{\circ}$ & 7.42 & $3.28^{c}$ & 15.91 & $8.63^{\circ}$ \\
\hline $\begin{array}{l}\text { Taste after label condition compared to taste before } \\
\text { label condition }\end{array}$ & 1,184 & .72 & .31 & .87 & .42 & .08 & .04 & .81 & .44 \\
\hline
\end{tabular}

\section{DISCUSSION}

Because our research deals with information framing effects, it seems only fitting that the present results can be stated in two different ways. On the one hand, the alternate labeling of a product attribute in positive or negative terms did affect consumers' evaluations even when they actually consumed the product. On the other hand, the labeling or framing effect was reduced when consumers sampled the product as compared to when they did not.

The framing influence of attribute labels, even when consumers can rely on their own experiences, serves to validate the information framing effect found in previous studies in which subjects evaluated hypothetical purchases (Bellizzi and Martin 1982; Levin et al. 1985). The general reduction of the framing effect that occurs when consumers actually sampled the product is consistent with the averaging model of information integration (see Shanteau 1988 for a similar model developed for combining temporal sequences of visual and verbal information). According to this model, the effect of any one source of information is decreased when it is combined with another source of information, because the two sources of information available to the judge are balanced in arriving at an integrated impression. The present results (Tables 1 and 2 ) clearly show this pattern. Verbal labels and experiential information thus appear to be combined through an averaging process. $^{2}$

'For the present situation, an averaging model can be formulated as follows: response $=\left(w_{f} f+w_{j} \ell\right) /\left(w_{f}+w_{e}\right)$, where $f$ and $e$ are the subjective scale values of the framed information and the personal experience, respectively, and $w_{f}$ and $w_{e}$ are the weights associated with these different sources of information. Two important features
Our results are also consistent with those of Hoch and $\mathrm{Ha} \mathrm{(1986),} \mathrm{who} \mathrm{found} \mathrm{that} \mathrm{ads} \mathrm{(frames)} \mathrm{have} \mathrm{an}$ effect on subsequent product evaluations only when the product experience is ambiguous. The question is whether tasting hamburger is an ambiguous experience. Examination of differences between rating scales reveals post hoc support for the relationship between ambiguity of experience and the frame (ad) effect proposed by Hoch and $\mathrm{Ha}$ (1986). One would expect that the "taste experience" would be most relevant to the bad tasting/good tasting scale and hence maximally reduce the framing effect, whereas the taste experience would be less relevant to the other scales. The results in Table 1 support this interpretation by showing the taste-related scale to be least (and nonsignificantly) affected by the frame when subjects actually tasted the meat.

The result from the Hoch and $\mathrm{Ha}$ (1986) study can be viewed within the averaging model framework. Product experience, whether it precedes or follows product information, will have the greatest weight when it is diagnostic (unambiguous). According to the balancing principle of the averaging model, we would then expect to find stronger framing (advertising) effects when the product experience is less diagnostic, such as sampling perfume or cologne.

The averaging model provides a context for examining a variety of factors (e.g., temporal effects) that

of this model should be noted. First, because the sum of the weights is in the denominator, the effective weight of information frame is $w_{j} /\left(w_{f}+w_{e}\right)$. which is less than one if $w_{e}$ is not equal to zero. This means that the effect of information frame is less when personal experience is provided than when it is not. Second, the weight parameters are allowed to vary with serial position (for example, which source of information is processed first) and by the salience or ambiguity of the attribute (as in Hoch and $\mathrm{Ha} \mathrm{1986).}$ 
would extend the current research. When various sources of information are integrated serially, the relative importance or weight of each source may depend upon its position within the sequence. The present trends suggest a primacy effect whereby the relative importance of attribute labeling is greater when it occurs before product consumption than when it occurs afterwards. This effect is consistent with the data reported by Hoch and $\mathrm{Ha}$ (1986), indicating that the impact of an ad presented before the product experience tends to be greater than the impact of one presented after. (As here, these differences supported a primacy effect, but were not significant.) The reliability of temporal effects needs to be affirmed in an expanded experimental design. The averaging model predicts that the weight of a given piece of information decreases as the number of pieces of information with which it is combined increases. Thus, the greater the number of prior personal experiences with a product, the less should be the effect of subsequent attribute labeling.

Because information weighting has been shown to vary directly with the polarity of the information presented (Levin et al. 1973), the quality of the personal experience should also moderate the effect of the product information frame. Thus, if the ground beef tastes terrible, for example, it is unlikely that even a powerful positive frame will lead to a favorable evaluation. Future research designed to test these predictions and quantify the effects of the variables of interest would involve manipulating the pleasantness of personal experiences with the product, as well as the relative number and temporal sequence of personal experiences and framed descriptions. Such research should serve to enhance our understanding of how consumers respond to advertisements and product experiences in the marketplace (Goering 1985).

\section{[Received March 1988. Revised July 1988.]}

\section{REFERENCES}

Allison, Ralph I. and Kenneth P. Uhl (1964), "Influence of Beer Brand Identification on Taste Perception," Journal of Marketing Research. 37 (April), 32-37.

Anderson, Norman H. (1981), Foundations of Information Integration Theory, New York: Academic Press.

- (1986), "A Cognitive Theory of Judgment and Decision," in New Directions in Research on Decision Making. eds. B. Brehmer, et al., Amsterdam, The Netherlands: North-Holland, 63-108.

Assael, Henry (1987), Consumer Behavior and Marketing Action, Boston, MA: Kent.

Bellizzi, Joseph A. and Warren S. Martin (1982), "The Influence of National Versus Generic Branding on Taste Perception," Journal of Business Research, 10 (September), 385-396.

Bettman, James R. (1979), Information Processing Theory of Consumer Choice, Reading, MA: Addison-Wesley.

- and C. Whan Park (1980), "Effects of Prior Knowledge and Experience and Phase of the Choice Process on Consumer Decision Processes: A Protocol Analysis," Journal of Consumer Research, 7 (December), 234-248.

- and Mita Sujan (1987), "Effects of Framing on Evaluation of Comparable and Noncomparable Alternatives by Expert and Novice Consumers," Journal of Consumer Research, 14 (September), 141-154.

Darley, John M. and Paget H. Gross (1983), "A HypothesisConfirming Bias in Labelling Effects," Journal of Personality and Social Psychology, 44 (January), 20-33.

Deighton, John (1984), "The Interaction of Advertising and Evidence," Journal of Consumer Research, 11 (December), 763-770.

and Robert M. Schindler (1988), "Can Advertising Influence Experience?” Psychology \&.Marketing, 5 (Summer), 103-115.

Goering, Patricia A. (1985), "The Effects of Product Trial on Consumer Expectations, Demand, and Prices," Journal of Consumer Research, 12 (June), 74-82.

Hoch, Stephen J. and Young-Won Ha (1986), "Consumer Learning: Advertising and the Ambiguity of Product Experience," Journal of Consumer Research, 13 (September), 221-233.

Johnson, Richard D. and Irwin P. Levin (1985), "More Than'Meets the Eye: The Effect of Missing Information on Purchase Evaluations," Journal of Consumer Re. search. 12 (September), 169-177.

Kahneman, Daniel and Amos Tversky (1979), "Prospect Theory: An Analysis of Decision Under Risk," Econometrica, 47 (March), 263-291.

Levin, Irwin P. (1987), "Associative Effects of Information Framing," Bulletin of the Psychonomics Society. 25 (March), 85-86.

- Richard D. Johnson, Craig P. Russo, and Patricia J. Deldin (1985), "Framing Effects in Judgment Tasks with Varying Amounts of Information," Organizational Behavior and Human Decision Processes, 36 (December), 362-377.

- Linda L. Wall, Jeanette M. Dolezal, and Kent L. Norman (1973), "Differential Weighting of Positive and Negative Traits in Impression Formation as a Function of Prior Experience," Journal of Experimental Psychology. 97 (January), 114-115.

Neale, M. and M. Bazerman (1985), "Perspectives for Understanding Negotiation: Viewing Negotiation as a Judgmental Process," Journal of Conflict Resolution, 29 (March), 33-55.

Puto, Christopher (1987), "The Framing of Buying Decisions," Journal of Consumer Research, 14 (December), $301-315$.

Shanteau, James (1988), "Consumer Impression Formation: The Integration of Visual and Verbal Information," in Nonverbal Communication in Advertising. eds. Sidney Hecker and David W. Stewart, Lexington, MA: D.C. Heath, 42-57.

Thaler, Richard (1985), "Mental Accounting and Consumer Choice," Marketing Science, 4 (Summer), 199214.

Troutman, C. Michael and James Shanteau (1976), "Do Consumers Evaluate Products by Adding or Averaging Attribute Information?" Journal of Consumer Research, 3 (September), 101-106.

Tversky, Amos and Daniel Kahneman (1981), "The Framing of Decisions and the Psychology of Choice," Science, 211 (September), 453-458. 
Copyright of Journal of Consumer Research is the property of Journal of Consumer Research. Inc. and its content may not be copied or emailed to multiple sites or posted to a listserv without the copyright holder's express written permission. However, users may print, download, or email articles for individual use. 